\title{
COMBINATION OF NOISE REMOVAL AND CONTRAST ENHANCEMENT METHODS FOR THE PREPROCESSING OF MAMMOGRAM IMAGES - TOWARDS THE DETECTION OF BREAST CANCER
}

\author{
COMBINAÇÃO DE MÉTODOS DE REMOÇÃO DE RUÍDO E APERFEIÇOAMENTO \\ DE CONTRASTE PARA O PRÉ-PROCESSAMENTO DE IMAGENS DE \\ MAMOGRAFIAS - RUMO À DETECÇÃO DO CÂNCER DE MAMA
}

\author{
B. SENTHILKUMAR ${ }^{1}$; R. GOWRISHANKAR ${ }^{1}$; M. VAISHNAVI $^{1}$; S. GOKILA $^{1}$ \\ 1. Professor, Department of Electronics and Communication Engineering, KIT-Kalaignarkarunanidhi Institute of Technology, \\ Coimbatore, Tamilnadu, India - 641 402. 2014senthilece@gmail.com,
}

\begin{abstract}
Breast cancer is a major killer disease for women and men. It can be treated and controlled only if it is detected at its earlier stage. Early detection can be achieved by the help of Computer Aided Detection (CAD) methods. From the detailed study on previous researches, it is found that, there is no system producing $100 \%$ accuracy because of one or more reasons. Absence of effective preprocessing is the discussed reason that obstructs the detection accuracy of CAD method. Noise removal and contrast enhancement are the two types of preprocessing. There is no system performs both the preprocessing on mammogram image. This work is an attempt to develop an enhanced preprocessing method for $\mathrm{CAD}$ of breast cancer by incorporating suitable noise reduction and contrast enhancement methods in the conventional CAD system. Among the available noise reduction techniques, Fast Discrete Curvelet Transform (FDCT) based UnequiSpaced Fast Fourier Transform (USFFT) has been utilized and the Modified Local Range Modification (MLRM) technique has been utilized for contrast enhancement. Contrast enhancement after noise reduction double enhances the mammogram image and the proposed methods MSE value for the mammogram image mdb072 has been $1.44 \%$ reduced when comparing to the LRM method. Reduction in MSE increases the PSNR to $0.16 \%$. Many mammogram images have been tested and the result shows that, increase in contrast, decrease in mean square error and increase in peak signal to noise ratio when comparing to existing methods.
\end{abstract}

KEYWORDS: Breast cancer. CAD. Preprocessing. USFFT. MLRM. Mammogram.

\section{INTRODUCTION}

Computer Aided Detection (CAD) is the main aid used by the radiologists in detecting the breast cancer. Preprocessing, segmentation and detection of suspicious regions are the main stages of a CAD. An x-ray like image has been observed from the human breast are called mammogram image, which is the input to CAD system. Many researchers proposed and tested many algorithms for the techniques used in the CAD and CADi. The detection efficiency of the existing methods is still to be improved to conclude about, whether the sample mammogram image is having cancer information or not. In this paper, new techniques for preprocessing have been proposed for the improvement of detection efficiency of CAD and compared with the existing techniques. Preprocessing of mammogram image consists of two important techniques. One is the noise removal and the other is enhancement by increasing the image quality. Many methods have been proposed and tested by researchers for both the techniques. (JACOB SCHARCANSKI; CLAUDIO ROSITO JUNG, 2006) investigated that, it is very hard to read masses in mammogram images because of its low contrast. Local Range Modification (LRM) for contrast enhancement has been tested by (PAPADOPOULOS et al., 2008). Statistical based enhancement has been tested by (DOMINGUEZ; NANDI, 2008) and (BIKESH KR SINGH, 2011). Denoising and enhancement by using generalized Gaussian mixture model in nonsubsampled contourlet transform has been performed by Xinsheng Zhang (2009). Many researchers have tested wavelet based systems for the removal of noise from digital mammogram. FDCT via wedge wrapping for noise reduction has been tested by (ANIL; JYOTI, 2010). (FARROKHBAKHT et al., 2012) tested an adaptive filter for noise cancelling in mammography images. Mammogram enhancement using wavelet transform has been tested by (HARISH KUMAR et al., 2012). The performance of various enhancement methods has been compared by (MORADMAND et al., 2012). From the detailed review, it is found that, the enhancement will be better only when both the preprocessing is performed simultaneously on mammogram image. But, there is no system performs both the preprocessing simultaneously because of time 
complexity. This paper is an attempt to perform both the enhancement methods. Curvelet based noise removal is done first and then modified LRM (MLRM) has been applied. This provides the enhancement of entire image with textures.

\section{MATERIALS AND METHODS}

Simulation of algorithms utilized in this work has been done by using MATLAB 7.0. The sample mammogram images used in this paper has been referred from Mammogram Image Analysis Society (MIAS) database and Digital Database for Screening Mammography (DDSM). Performance of proposed preprocessing method has been evaluated by calculating Mean Square Error (MSE), Peak Signal to Noise Ratio (PSNR) and Contrast value.

\section{Fast Discrete Curvelet Transform via UneqiSpaced Fast Fourier Transform (FDCT via USFFT) for Noise Reduction}

This is one of the curvelet based method utilized in this work for the noise reduction in digital mammogram images. Curvelet form an effective model that not only considers a multiscale time frequency local partition but also use geometric feature direction. This transform was designed to represent edges and other singularities along curves much more efficiently than wavelet transform. Wavelets provide sparse and efficient representation of smooth signals and it cannot efficiently represent the discontinuities along edges and curves in mammogram images. And many wavelet coefficients are required to reconstruct the edges in an image properly. Because of this, wavelets are not able to produce accurate result. Ridgelet transforms provides a sparse representation of both smooth functions and of perfectly straight edges. In mammogram image processing, edges are curved rather than straight and ridgelets alone cannot yield efficient representations. So, ridgelet in multiscale called curvelet, is used in this research. The USFFT version uses a decimated rectangular grid tilted along the main direction of each curvelet and for the digital transform tilting the grids induces a resampling of the Fourier transform on semi regular grids. For the inversion a conjugate gradient solver rapidly converges to the solution. This made the filter capable of removing almost all the types of noises presented in mammogram images.

Performance of this method has been tested by calculating two important error metrics. They are MSE and PSNR given in equation (1) and (2) respectively. The MSE is cumulative squared error between the processed and the original image and PSNR is a measure of the peak error.

$M S E=\frac{1}{M N} \sum_{y=1}^{M} \sum_{x=1}^{N}\left[I(x, y)-I^{\prime}(x, y)\right]^{2}$
$P S N R=10 \log _{10}\left\{\frac{255^{2}}{M S E}\right\}=20 \log _{10}\left\{\frac{255}{\sqrt{M S E}}\right\}$

Here, $I(x, y)$ is the original image and $I^{\prime}(x, y$ is the approximated version of processed image. $\mathrm{M}$ and $\mathrm{N}$ are the dimensions of the images. Noise removed image can be processed further for the enhancement of contrast by using the MLRM method.

\section{Modified Local Range Modification (MLRM) for Contrast Enhancement}

Noise reduced mammogram image has been further processed by MLRM method. The MLRM method has been derived from Local Range Modification (LRM) method tested by (PAPADOPOULOS et al., 2008). It is a linear stretching approach follows the formula $\mathrm{y}=\mathrm{ax}+\mathrm{b}$, where $\mathrm{y}$ is the enhanced image, $\mathrm{x}$ is the original grayscale image and $\mathrm{a}, \mathrm{b}$ are parameter depending on the local contrast, which are computed by an interpolation procedure using overlapping image blocks. The Modifed Local Range Modification (MLRM) algorithm has been tested by (SENTHILKUMAR; UMAMAHESWARI, 2013) and works similar to that of LRM method but with two changes adopted. They are the maximum and minimum pixel values of non overlapping $48 * 48$ pixel size blocks are computed during first pass instead of $51 * 51$ in LRM and the estimation of regional maximum and minimum values has been computed based on the interpolation of eight surrounding grids instead of four points in LRM. Since the estimation of regional values is done based on the interpolation of four surrounding grid points, there may be a possibility of missing the pixels in the corner of the image. To overcome this problem, eight surrounding grid points instead of four in LRM has been tested with $48 * 48$ pixel block size in the MLRM method. The modifications performed in the LRM method enhanced the image better than the other methods. The proposed MLRM method have been applied to different mammogram images, results have been compared with the unenhanced mammogram image and presented in the results section.

\section{RESULTS AND DISCUSSION}

The proposed noise reduction method performs well on digital mammogram images and 
the output is better than the other existing noise reduction methods. Calculation of MSE and PSNR has been performed by using the equations 1 and 2 . The calculated values for three sample mammogram images are tabulated in table 1 . Form the table 1, it is clearly known that the MSE of the proposed FDCT - USFFT method is reduced to a value of 7.43 and the PSNR value is increased to 39.42 for mammogram image mdb075. But for the same image, it is found larger MSE values and smaller PSNR values for other existing methods like selective median filtering, adaptive median filtering and FDCT wedge wrapping. Hence, this new algorithm improves the image quality by reducing the noise and outperforms the performance of all other existing methods.

Table 1. MSE and PSNR comparison of proposed noise reduction method with the existing methods.

\begin{tabular}{l|l|l|l|l|l|l}
\hline \multirow{2}{*}{ Noise Reduction Techniques } & \multicolumn{2}{l}{ Mdb075 } & \multicolumn{2}{l}{ Mdb072 } & \multicolumn{2}{l}{ Mdb322 } \\
\cline { 2 - 7 } & MSE & PSNR & MSE & PSNR & MSE & PSNR \\
\hline Without Noise Removal & 396.11 & 22.15 & 397.56 & 22.14 & 391.34 & 22.21 \\
\hline Selective Median Filtering & 204.76 & 25.02 & 205.97 & 24.99 & 201.15 & 25.10 \\
\hline Adaptive Median Filtering & 154.17 & 26.25 & 156.81 & 26.18 & 142.78 & 26.58 \\
\hline FDCT - wedge wrapping & 29.52 & 33.43 & 34.93 & 32.70 & 25.62 & 34.05 \\
\hline Proposed Method (FDCT - USFFT) & 7.43 & 39.42 & 9.16 & 38.51 & 6.78 & 39.82 \\
\hline
\end{tabular}

The resulted images of many different mammogram images with different intensity level have been tested and the result of mammogram image mdb072 has been given in the following figure.
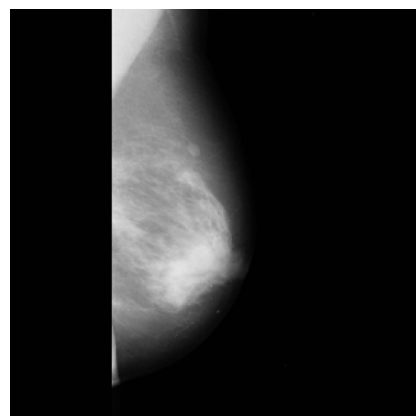

(a) Input Image

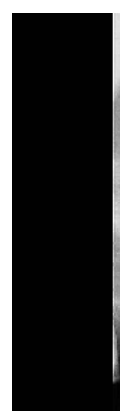

(b) FDCT - Wedge Wrapping Image

Figure 1. Result of proposed noise reduction method for mdb072

(c) FDCT - USFFT Image
From figure 1, (a) is the original mammogram input image, (b) is the FDCT - wedge wrapping output image and (c) is the FDCT USFFT output image. The image in (c) is better in clarity than the images in (a) and (b).

Six contrast enhancement methods have been discussed in this work. The proposed image enhancement algorithm not only improves the contrast, it also involving in reduction of noise. That is the main reason behind choosing this algorithm after the noise reduction. Contrast value, MSE and PSNR have been calculated for the methods discussed. The contrast has been measured by the ratio of difference between foreground and background mean gray level to sum of foreground and background mean gray level. The percentage of contrast improvement has been given in table 2 .

Table 2. Percentage of contrast improvement

\begin{tabular}{l|l|l|l}
\hline \multirow{2}{*}{ Contrast Enhancement Techniques } & \multicolumn{3}{|l}{ Contrast Percentage } \\
\cline { 2 - 4 } & Mdb75 & Mdb72 & Mdb322 \\
\hline LRM & 10.50 & 16.99 & 4.81 \\
\hline Proposed Method (MLRM) & 13.08 & 20.49 & 6.12 \\
\hline
\end{tabular}


The LRM method has increased the contrast to $10.5 \%$ for the test mammogram image mdb75, $16.99 \%$ for mdb72 and $4.81 \%$ for mdb322. But the proposed MLRM method increases the contrast further to $13.08 \%$ for $\mathrm{mdb} 75,20.49 \%$ for $\mathrm{mdb} 72$ and $6.12 \%$ for mdb322. This is comparatively better than the other methods discussed. Table 3 is having MSE and PSNR values. Proposed method enhances the image with lower MSE and higher PSNR with increase in contrast.

Table 3. MSE and PSNR comparison of proposed contrast enhancement method with the existing methods

\begin{tabular}{l|l|l|l|l|l|l}
\hline \multirow{2}{*}{ Contrast Enhancement Techniques } & Mdb075 & \multicolumn{2}{l}{ Mdb072 } & \multicolumn{3}{l}{ Mdb322 } \\
\cline { 2 - 7 } & MSE & PSNR & MSE & PSNR & MSE & PSNR \\
\hline Without Enhancement & 7.43 & 39.42 & 9.16 & 38.51 & 6.78 & 39.82 \\
\hline CLAHE & 7.41 & 39.43 & 9.14 & 38.52 & 6.71 & 39.86 \\
\hline WLS & 7.39 & 39.44 & 9.13 & 38.53 & 6.67 & 39.89 \\
\hline WBA & 7.38 & 39.45 & 9.09 & 38.55 & 6.65 & 39.90 \\
\hline WS & 7.36 & 39.46 & 9.05 & 38.56 & 6.62 & 39.92 \\
\hline LRM & 7.32 & 39.49 & 9.04 & 38.57 & 6.57 & 39.96 \\
\hline Proposed Method (MLRM) & 7.14 & 39.59 & 8.91 & 38.63 & 6.46 & 40.03 \\
\hline
\end{tabular}

Image without enhancement, Contrast Limited Adaptive Histogram Equalization (CLAHE), Wavelet Linear Stretching (WLS), Wavelet Background Approximation (WBA), Wavelet Shrinkage (WS) and the Local Range Modification (LRM) methods have been compared with the proposed MLRM method and tabulated in table 3. The FDCT - USFFT and MLRM

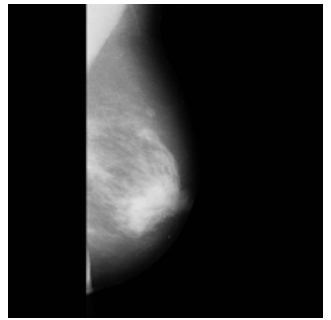

(a) Input Image

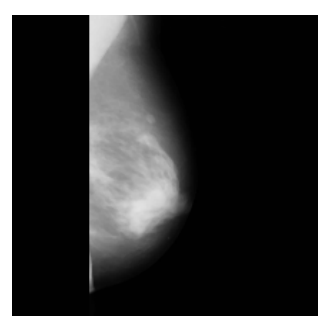

(b) FDCT - USFFT Image
Figure 2. Result of MLRM enhancement for mdb072

Here from figure 2, (a) is the original mammogram input image, (b) is the FDCT USFFT image, (c) is the LRM enhanced output and (d) is the MLRM enhanced output image and it looks more clear than the image in (c). Contrast enhancement after noise reduction double enhances the mammogram image and the proposed methods MSE value for the mammogram image mdb072 has been $1.44 \%$ reduced when comparing to the LRM method. Reduction in MSE increases the PSNR to $0.16 \%$. This performance has been acted as an important one in the detection accuracy improvement of the CAD method. combination enhances the mammogram better for further processing. From the comparison results shown in Table 3, it is clearly indicated that the proposed method have performed well on mammogram images for the better enhancement. Result of sample mammogram image has been shown in the following figure.

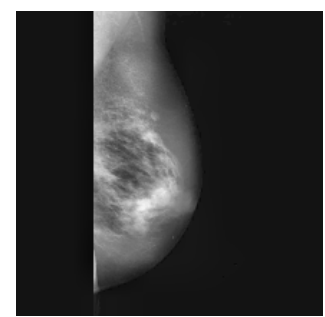

(c) LRM Enhanced Image

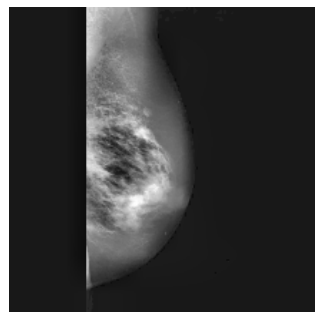

(d) MLRM Enhanced Image

\section{CONCLUSIONS}

This paper describes new methods for noise removal and contrast enhancement in digital mammogram image for the effective detection of breast cancer. Digital implementation of FDCT via USFFT has been done for the reduction of noise and enhancement of digital mammogram image. The preprocessing is particularly designed for the enhancement of gray level intensity of suspicious masses and to eliminate the noise effects by making use of curvelet filter and MLRM method. Curvelet transform are used as a multiscale level decomposition to represent the mammogram images and it is capable of capturing the multi dimensional features. This helps for the classification of features from mammogram images. This curvelet approach not only reduces the Gaussian noise but it also can 
be applied to non Gaussian noise models. Noise reduction has also been achieved by optimal contrast modification by using MLRM method. Performance of the proposed noise reduction method has been analyzed based on the calculation of MSE and PSNR. For example, MSE reduction of $75 \%$ and PSNR increase of $17.92 \%$ has been achieved for the sample mammogram image mdb075. The comparison result for the noise reduction method shows that, proposed noise reduction method reduced the MSE and improved the PSNR for the images tested. Six contrast enhancement methodologies have been examined for the mammogram enhancement and improvement has been made to increase the performance of existing $\mathrm{CAD}$ system for the detection of breast cancer.

The modification done in the LRM enhancement method enhances the mammogram image by improving the contrast and reduces the noise remains in the image. The proposed MLRM uses eight surrounding pixels instead of four in LRM. Time complexity of the proposed method may increase because of it. But the image quality found is good and satisfactory when comparing to LRM. Contrast value, MSE and PSNR have been calculated and compared with the existing contrast enhancement methods. The resulted value shows that the proposed method performs well on mammogram image in improving the contrast and reducing the noise with good extraction of edges. The contrast has been improved to a range of $6-21 \%$ for different mammogram images. Further reduction in MSE to an amount of 1-3\% and improvement in PSNR to an amount of $0.1-0.3 \%$ has been achieved because of the proposed MLRM enhancement method. This achievement is an addition to the noise removal method discussed in this paper. In future, it is planned to implement this enhanced preprocessing method in Field Programmable Gated Array (FPGA).

\begin{abstract}
RESUMO: Introdução: O câncer de mama é uma grande doença mortal para mulheres e homens. Ele só pode ser tratado e controlado se for detectado em sua fase inicial. A detecção precoce pode ser alcançada com a ajuda de métodos de detecção assistida por computador (CAD). A partir do estudo detalhado sobre pesquisas anteriores, verifica-se que, não há um sistema com $100 \%$ de precisão por causa de uma ou mais razões. A ausência de pré-processamento efetivo é o motivo discutido que obstrui a precisão de detecção do método CAD. A remoção de ruído e o aprimoramento do contraste são os dois tipos de pré-processamento. Não existe um sistema que realize ambos os pré-processamentos na imagem da mamografia. Objetivo: Este trabalho é uma tentativa de desenvolver um método de pré-processamento aprimorado para CAD de câncer de mama, incorporando métodos adequados de redução de ruído e aprimoramento de contraste no sistema de CAD convencional. Métodos: Entre as técnicas de redução de ruído disponíveis, a transformada de curva discreta rápida (FDCT) baseada na transformada rápida de Fourier desigualmente espaçada (USFFT) foi utilizada e a técnica de modificação de faixa local modificada (MLRM) foi utilizada para aprimoramento de contraste. Resultados: o aprimoramento do contraste após a redução do ruído melhora o dobro da imagem da mamografia e os métodos propostos para o valor de MSE para a imagem da mamografia mdb072 foram reduzidas em 1,44\% quando comparados ao método LRM. A redução de MSE aumenta o PSNR para 0,16\%. Conclusão: muitas imagens de mamografia foram testadas e o resultado mostra que, aumento no contraste, diminuição do erro quadrático médio e aumento da relação pico do sinal/ruído quando comparado aos métodos existentes.
\end{abstract}

PALAVRAS-CHAVE: Câncer de mama. CAD. Pré-processamento. USFFT. MLRM. Mamograma.

\title{
REFERENCES
}

SCHARCANSKI, J.; JUNG, C. R. Denoising and enhancing digital mammographic images for visual screening. Computerized Medical Imaging and Graphics, v. 30, n. 4, p. 243-254, 2006.

https://doi.org/10.1016/j.compmedimag.2006.05.002

DOMINGUEZ, A. R; NANDI, A. K. Detection of masses in mammogram via statistically based enhancement, multilevel-thresholding segmentation and region selection. Computerized Medical Imaging and Graphics, v. 32, n. 4, p. 304-315, 2008. https://doi.org/10.1016/j.compmedimag.2008.01.006

SINGH, B. K. Mammographic image enhancement, classification and retrieval using color, statistical and spectral analysis. International Journal of Computer Applications, v. 27, n. 1, p. 18-23, 2011. 
PAPADOPOULOS, A.; FOTIADIS, D. I.; COSTARIDOU, L. Improvement of microcalcification cluster detection in mammography utilizing image enhancement techniques. Computers in Biology and Medicine, v. 38, n. 10, p. 1045-1055. 2008. https://doi.org/10.1016/j.compbiomed.2008.07.006

ZHANG, X. Mammograms enhanced and denoising using generalized Gaussian mixture model in nonsubsampled contourlet transform domain. Journal of Multimedia, v. 4, n. 6, p. 389-396. 2009. https://doi.org/10.4304/jmm.4.6.389-396

ANIL, A. P.; JYOTI, S. Image denoising using curvelet transform: an approach for edge preservation. Journal of Scientific and Industrial Research, v. 69, n. 1, p. 34-38, 2010.

FARROKHBAKHT, H.; MASOUMZADEH, T. A.; YAZDAN, T.; RAMEZANPOUR, H; DARMANI G. An adaptive filter for noise cancelling in mammography images based on cellular automata. International Review on Modeling and Simulations, v. 5, n. 3, p. 1322-1326, 2012.

HARISH KUMAR N; AMUTHA S; RAMESH BABU D. Enhancement of mammographic images using morphology and wavelet transform. International Journal of Computer Technology and Applications, v. 3, n. 1, p. 192-198; 2012.

MORADMAND H; SETAYESHI S; KARIMIAN AR; SIROUS M; AKBARI ME. Comparing the performance of image enhancement methods to detect microcalcification clusters in digital mammography. Iran Journal of Cancer Prevention, v. 5, n. 2, p. 61-68, 2012.

SENTHILKUMAR B; UMAMAHESWARI G. Combination of Novel Enhancement Technique and Fuzzy C Means Clustering Technique in Breast Cancer Detection. Biomedical Research, v. 24, n. 2, p. 252-256, 2013. 